\title{
Microbiological safety of a novel bio-artificial liver support system based on porcine hepatocytes: a experimental study
}

Bing Han ${ }^{1,2+}$, Xiao-lei Shi ${ }^{1,2+}$, Yue Zhang ${ }^{2,1}$, Xue-hui Chu ${ }^{1,2}$, Jin-yang Gu ${ }^{1,2}$, Jiang-qiang Xiao ${ }^{1}$, Hao-zhen Ren ${ }^{1}$, Jia-jun Tan ${ }^{1}$, Zhong-ze $\mathrm{Gu}^{3}$ and Yi-tao Ding ${ }^{1,2^{*}}$

\begin{abstract}
Background: Our institute has developed a novel bio-artificial liver (BAL) support system, based on a multi-layer radial-flow bioreactor carrying porcine hepatocytes and mesenchymal stem cells. It has been shown that porcine hepatocytes are capable of carrying infectious porcine endogenous retroviruses (PERVs) into human cells, thus the microbiological safety of any such system must be confirmed before clinical trials can be performed. In this study, we focused on assessing the status of PERV infection in beagles treated with the novel BAL.

Methods: Five normal beagles were treated with the novel BAL for 6 hours. The study was conducted for 6 months, during which plasma was collected from the BAL and whole blood from the beagles at regular intervals. DNA and RNA in both the collected peripheral blood mononuclear cells (PBMCs) and plasma samples were extracted for conventional PCR and reverse transcriptase (RT)-PCR with PERV-specific primers and the porcinespecific primer Sus scrofa cytochrome B. Meanwhile, the RT activity and the in vitro infectivity of the plasma were measured.
\end{abstract}

Results: Positive PERV RNA and RT activity were detected only in the plasma samples taken from the third circuit of the BAL system. All other samples including PBMCs and other plasma samples were negative for PERV RNA, PERV DNA, and RT activity. In the in vitro infection experiment, no infection was found in HEK293 cells treated with plasma.

Conclusions: No infective PERV was detected in the experimental animals, thus the novel BAL had a reliable microbiological safety profile.

Keywords: Microbiological safety, Porcine endogenous retrovirus, Bio-artificial liver, Porcine hepatocyte, Mesenchymal stem cells

\section{Background}

Acute liver failure (ALF) is a serious clinical disease with high mortality rate. Although liver transplantation is currently recognized as the most effective treatment for ALF, its application has been seriously limited by the lack of donor organs, the high cost of treatment, and the

\footnotetext{
* Correspondence: yitaoding@hotmail.com

${ }^{\dagger}$ Equal contributors

'Department of Hepatobiliary Surgery, the Affiliated DrumTower Hospital of Nanjing University Medical School, Number 321 Zhongshan Road, Nanjing 210008, China

${ }^{2}$ Department of Hepatobiliary Surgery, DrumTower Clinical Medical College of Nanjing Medical University, Number 321 Zhongshan Road, Nanjing 210008, China

Full list of author information is available at the end of the article
}

requirement for life-long immunosuppressive therapy $[1,2]$. Therefore, bio-artificial liver (BAL) support systems, based on functional hepatocytes, have received extensive attention because of their unique biological function, and considerable progress has been made in their development [3-5]. Currently, porcine hepatocytes are still the main cell sources for such systems because of their adequate resources, accessibility, and features similar to human hepatocytes [6-8]. However, because they are xenogeneic cells, porcine hepatocytes are associated with a number of problems, including that of microbiological safety. Porcine endogenous retrovirus (PERV) was first discovered in 1971 in porcine kidney 
(PK15) cells [9]. In 1997, Patience et al. showed for the first time that PERV released from PK15 could infect human embryonic kidney (HEK)293 cells in vitro [10]. Subsequently, PERV-A and PERV-B were confirmed as the human-tropic subtypes [11]. It was later found that PERV could successfully infect a variety of human cells in vitro, including endothelial cells, fibroblasts and bone marrow stromal cells, and virus replication was seen in some of these cells. Two other in vivo studies showed that implanted porcine islets could result in PERV infection in non-obese diabetic/severe combined immunodeficiency (NOD/SCID) mice [12]. Thus, transmission of PERV is a microbiological safety issue that cannot be ignored in BAL systems using porcine hepatocytes.

We developed a novel multi-layer radial-flow bioreactor containing galactosylated chitosan nanofiber scaffolds, which we found to have a high level o fefficiency in vitro [13]. The bioreactor is composed of a stack of 65-layer round flat plates and a cylindrical container with an inlet on the top and an outlet on the bottom. A coculture system of porcine hepatocytes and mesenchymal stem cells (MSCs), which had been established previously in our institute [14], was perfused into the bioreactor to act as functional cells, and a new extracorporeal BAL support system based on the novel multi-layer radial-flow bioreactor and the co-culture system of porcine hepatocytes and MSCs. was constructed. This study is a preclinical experiment identifying the microbiological safety of the novel BAL. In this study, we used five normal dogs to assess transmission of PERV. The aim of this research was to investigate whether there was a possibility of transmission of PERV into the experimental dogs using this new BAL support system.

\section{Methods}

\section{Animals and reagents}

All animal procedures were performed in accordance with institutional and national guidelines and with the approval by the Animal Care Ethics Committee of Nanjing University and Nanjing Drum Tower Hospital.

Five outbred white pigs with an average weight of 15$20 \mathrm{~kg}$ and five inbred beagles with an average weight of 11-13 kg were used for the experiments.

All cell culture-related reagents were purchased from Gibco (Grand island, N.Y.USA).

\section{Establishing co-culture system of porcine hepatocytes and mesenchymal stem cells}

A co-culture system of porcine hepatocytes and MSCs was prepared as described previously [14]. In brief, bone marrow was aspirated from the iliac crest of the pigs, then the mononuclear cells were collected over a Ficoll histopaque layer by gradient centrifugation (20 minutes, $400 \mathrm{~g}$, density $1.077 \mathrm{~g} / \mathrm{ml}$ ) and seeded at a density of $1 \times 10^{6} \mathrm{cells} / \mathrm{cm}^{2}$ in growth medium containing low-glucose DMEM supplemented with $10 \% \mathrm{FBS}, 100 \mathrm{IU} / \mathrm{ml}$ penicillin and $100 \mathrm{mg} /$ $\mathrm{ml}$ streptomycin. The culture medium was replaced after the first 24 hours, and the subculture was prepared according to standard cell-culture techniques. The cultured cells were confirmed as MSCs by analysis (FACScan; Becton Dickinson, San Jose, CA, USA) of surface markers, including CD45, CD29, CD44, and CD90. The primary pig hepatocytes were harvested using a two-step in situ collagenase perfusion technique. The viability of the isolated primary hepatocytes, as determined by trypan blue exclusion, was greater than $95 \%$. Non-parenchymal cells were identified based on size ( $<10 \mu \mathrm{m}$ in diameter) and morphology (nonpolygonal or stellate), and made up less than $1 \%$ of cells, which was confirmed by immunocytochemical analysis of albumin and cytokeratin 18. The mixed suspension of fresh hepatocytes and MSCs during passages 3 to 5 (2:1) was perfused at a density of $10^{6}$ cells $/ \mathrm{ml}$ into a substratum of $500 \mathrm{ml}$ RPMI-1640 without sera, and incubated in our new bioreactor at $37^{\circ} \mathrm{C}$ and $5 \% \mathrm{CO}_{2}$.

\section{Construction and application of the new bio-artificial liver support system}

The new BAL support system consisted of three roller pumps, a heparin pump, an infusion heater, a plasma filter (Sorin Group Italia, Mirandola, Italy), a plasma component separator (Kawasumi Laboratories Inc, Tokyo, Japan) serving as immunoprotective barrier, an oxygenation device, and a multi-layer radial-flow bioreactor containing galactosylated chitosan nanofiber scaffolds. The bioreactor and the oxygenation device was prepared and kept in an incubator with am internal temperature of $37^{\circ} \mathrm{C}$ as previously reported [13]. The whole system was then assembled as shown in Figure 1.

Catheters were inserted into the internal carotid artery and internal jugular vein of the dogs under continued anesthesia by intravenous administration of propofol (Diprivan; Astrazeneca, Wuxi, China) at a dose of $10 \mathrm{mg} / \mathrm{kg} / \mathrm{h}$, and the catheters were then connected to the BAL device (Figure 1). The BAL treatment was begun 4 hours after the cells were seeded, when most cells were adhered to the galactosylated chitosan nanofiber scaffolds. During the first circuit, the whole blood in was perfused at a rate of $40 \mathrm{ml} / \mathrm{min}$ for 6 hours, then during the second circuit, the plasma was separated from the plasma filter at a rate of $15 \mathrm{ml} / \mathrm{min}$, and finally during the third circuit, the plasma was filtered through the plasma component separator at a rate of $15 \mathrm{ml} / \mathrm{min}$. Heparin $(100 \mathrm{U} / \mathrm{kg})$ was administered intravenously to the dogs at the start of treatment and continued at a dose of $40 \mathrm{U} / \mathrm{kg} / \mathrm{h}$ into the first circuit, and removed 30 minutes before the end of the treatment. Samples of the plasma circulating in the BAL system and samples of whole blood from the beagles were collected at regular 


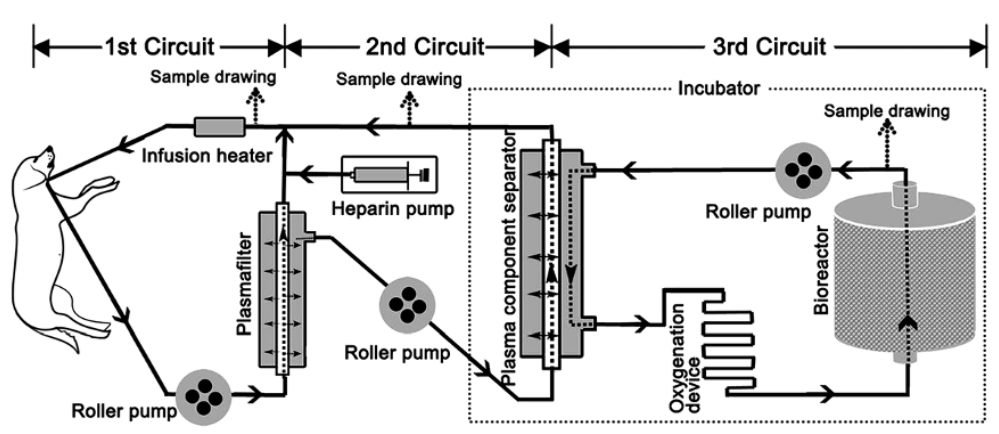

Figure 1 Construction of the bio-artificial liver support system. The system consists of three roller pumps, a heparin pump, an infusion heater, a plasmafilter, a plasma component separator, an oxygenation device, and a multi-layer radial-flow bioreactor containing galactosylated chitosan nanofiber scaffolds. The bioreactor and the oxygenation device is kept in an incubator with the internal temperature of $37^{\circ} \mathrm{C}$. All devices are connected by sterile tubing. The dotted arrow indicates where the samples were drawn into the circuits.

intervals (before treatment, at 3 and 6 hours during treatment, and at 12 hours, 1, 3, 5 and 7 days, 2, 3, and 4 weeks, and 3 and 6 months after treatment) until the research was completed 6 months after the treatment. Complete blood count (CBC) was assessed for each blood sample. PBMCs and plasma were separated from the whole blood, and frozen at $-80^{\circ} \mathrm{C}$ for later use.

\section{DNA extraction and PCR}

Total DNA was extracted from the plasma and the separated PBMCs by means of a DNA extraction kit (Axygen Scientific Inc.,Union City, CA, USA) in accordance with the manufacturer's instructions, using the primers shown in Table 1 [15,16]. PCR conditions were $50^{\circ} \mathrm{C}$ for $30 \mathrm{~min}$ utes, then $95^{\circ} \mathrm{C}$ for 5 minutes, followed by 35 cycles of $94^{\circ} \mathrm{C}$ for 30 seconds, $55^{\circ} \mathrm{C}$ for 45 seconds, $72^{\circ} \mathrm{C}$ for 30 seconds, with a final extension step of $72^{\circ} \mathrm{C}$ for 5 minutes. Samples were separated by gel electrophoresis in $2 \%$ agarose gels and stained with ethidium bromide. DNA and RNA extracted from PK15 cells was used as positive control and pure water as negative control.

\section{RNA extraction and reverse transcriptase PCR}

Total RNA was extracted from the PBMCs and the plasma with Trizol reagent (Invitrogen Inc., Carlsbad, USA), and dissolved in diethyl pyrocarbonate-treated water in accordance with the manufacturer's instructions. The extracted RNAs had an OD 260/280 of 1.60 and 2.00, respectively. DNAs were reverse-transcribed to cDNA using commercial kits (Biouniquer Technology Co.,Ltd, Hongzhou, China) in accordance with the manufacturer's instructions, then PCR was performed as described above.

\section{Reverse transcriptase activity assay}

The RT activity of the plasma was assessed using a commercial kit (C-type RT activity Kit; Cavidi-Tech, Uppsala,
Sweden), in accordance with the manufacturer's instructions.

\section{Exposure of canine peripheral blood mononuclear cells to porcine endogenous retrovirus}

PERV was harvested from the supernatant of PK15 cells and concentrated by sucrose density-gradient centrifugation [17]. Canine PBMCs isolated from the blood of normal dogs were exposed to PERV in a culture medium composed of $1 \mathrm{ml}$ PERV and $4 \mathrm{ml}$ of high-glucose DMEM with $0.8 \mathrm{~g} / \mathrm{ml}$ polybrene (hexadimethrine bromide; Sigma Aldrich) for 24 hours. The cells were then washed with PBS twice, and subcultured for 1 month. Finally, the cells were collected for assessment of PERV by PCR, RT-PCR and RT activity assay. Previously. The infected cells were used as a positive control.

\section{In vitro infection experiments}

The in vitro infection experiments were performed as described previously [18], with some modifications HEK293 cells (gift from Professor Hua, Nanjing University) were passaged overnight in $25-\mathrm{ml}$ tissue culture flasks and then incubated in a culture composed of $2 \mathrm{ml}$ of separated plasma harvested at defined times, and $3 \mathrm{ml}$ of DMEM-HG with $0.8 \mathrm{~g} / \mathrm{ml}$ polybrene. Meanwhile, the supernatant of PK15 cells and $0.8 \mathrm{~g} / \mathrm{ml}$ polybrene was inoculated into the culture of HEK293 cells as a positive control. After 4 hours of exposure at $37^{\circ} \mathrm{C}$, the inoculum was removed, and the cell monolayer was washed twice with PBS. The cells were then cultured with high-glucose DMEM supplemented with $10 \%$ FBS, and passaged to confluence for 1 month before collection. The collected HEK293 cells were tested for PERV DNA by PCR. RT activity was measured in the supernatant of treated HEK293 cells. 
Table 1 Primers used for PCR

\begin{tabular}{lll}
\hline Name & Direction & Sequence $\mathbf{5}^{\prime} \rightarrow \mathbf{3}^{\prime}$ \\
\hline Protease-specific & Forward & GCTACAACCATTAGGAAACTAAAAG \\
& Reverse & AACCAGGACTGTATATCTTGATCAG \\
Polymerase-specific & Forward & CTACAACCATTAGGAAAACTAAAAG \\
& Reverse & AACCAGGACTGTATATCTTGATCAG \\
SsCytB & Forward & CATTGGATAGTCCTACTATTACCG \\
& Reverse & GTAGGATTAGTATTATAAATAAGGCTCCT \\
B-actin & Forward & GCTCGTCGTCGACAACGGCTC \\
& Reverse & CAAACATGATCTGGGTCATCTTCTC \\
\hline
\end{tabular}

SsCytB, Sus scrofa cytochrome B.

\section{Results}

Status of animals receiving bio-artificial liver treatment Animals had their heart and respiratory rates monitored continuously by an electrocardiography, and these were stable during the extracorporeal perfusion. All dogs were able to stand and take food within 12 hours from the end of the treatment., and their biological behavior recovered to the pre-treatment state within 72 hours. All animals survived throughout the entire 6-month study.

\section{Complete blood count}

The results of the CBC are listed in Table 2.

\section{Detection of porcine endogenous retrovirus DNA and RNA in peripheral blood mononuclear cells}

The agarose gel electrophoresis results showed that there was no PERV DNA or RNA in the dog PBMCs collected at various times. Screening for the porcine-specific gene SsCytB did not find this gen in the DNA of the PBMCs of any of the five dogs (Figure 2).

\section{Detection of porcine endogenous retrovirus DNA and RNA in plasma}

Except for positive bands representing the protease and polymerase gene in circuit 3 before and during treatment, all results of RT-PCR with the RNA from collected plasma were negative (Figure 3 ). The same results were obtained for plasma DNA, and no SsCytB sequence was seen in the plasma.

\section{Reverse transcriptase activity assay}

The RT activity was examined twice for all collected plasma samples. The results showed that the RT activity was limited to the plasma in the third circuit before and at 3 hours of treatment. RT activity was not detected in any the other samples including all dog plasma collected during and after the treatment (Table 3).

\section{Infection of HEK293 cells in vitro}

Results were negative for PERV-specific genes including protease and polymerase genes and the porcine-specific SsCytB sequence in the DNA from HEK293 cells inoculated with collected plasma. DNA extracted from PK15infected HEK293 cells and the pure water was used as positive control and negative control, respectively. All supernatants from treated HEK293 cells were negative for RT activity.

\section{Discussion}

We report the development of a novel BAL system based on a new multi-layer radial-flow bioreactor containing galactosylated chitosan nanofiber scaffolds and a co-system of porcine hepatocytes and MSCs. This was developed in our institute because clinical trials of other BAL systems have shown disappointing results $[3,4]$. To improve the cellular function, each plate was covered with nanofiber scaffolds to mimic the topography of extracellular matrix (ECM), and the galactose was grafted onto the nanofibers to mimic the biochemical environment of ECM [13]. We used a co-culture system of porcine hepatocytes and MSCs at a ratio of $2: 1$, which was introduced into the BAL system [14]. Both of these two elements have been shown to have better hepatoctye-specific function in vitro, so we expected our BAL to be superior to previous devices. A plasma component separator was placed between circuits 2 and 3 to allow with media exchange by passive diffusion across the semipermeable membrane inside, as with other BAL systems [4].

PERV is known to exist generally in the porcine genome. Various porcine cells can excrete PERV particulates, which have been shown to infect a variety of human cells in vitro [12], and a transient PERV infection in guinea pigs was seen in vivo [19]. Previous reports

Table 2 Complete blood count of dogs with bio-artificial liver treatment

\begin{tabular}{|c|c|c|c|}
\hline Time points & White blood cells, $\times 10^{9} / \mathrm{I}$ & Red blood cells, $\times 10^{12} / l$ & Platelets, $\times 10^{12} / /$ \\
\hline Before treatment & $13.0 \pm 4.72$ & $5.6 \pm 1.27$ & $252.1 \pm 100.22$ \\
\hline After 3 hours of treatment & $9.2 \pm 9.56$ & $6.9 \pm 1.44$ & $159.9 \pm 106.28$ \\
\hline $6 \mathrm{~h}$ during treatment & $33.7 \pm 6.20$ & $7.2 \pm 0.76$ & $244.0 \pm 76.47$ \\
\hline 1 day after treatment & $29.4 \pm 12.16$ & $7.2 \pm 0.98$ & $229.72 \pm 99.63$ \\
\hline 3 day after treatment & $17.9 \pm 8.04$ & $5.6 \pm 1.16$ & $205.3 \pm 161.58$ \\
\hline 7 day after treatment & $17.3 \pm 5.36$ & $4.6 \pm 1.18$ & $214.3 \pm 159.55$ \\
\hline
\end{tabular}






Figure 2 Representative results of PCR electrophoresis with the DNA of beagle peripheral blood mononuclear cells (PBMCs). No PERV DNA or Sus scrofa cytochrome B (SsCytB) sequence was found in the canine PBMCs. DNA from porcine hepatocytes and PERVinfected canine peripheral blood mononuclear cell (PBMCs) were used as positive controls, and pure water was used as the negative control. Ladder ranged from 100 to $600 \mathrm{bp}$.

claimed infection in severe combined immunodeficiency mice $[20,21]$ and nude mice [22] after injection of porcine islet cells. Pseudotyping with murine endogenous retroviruses has been shown to be the mechanism of transmission $[23,24]$. It was found that dogs possess the same huPAR-1 and muPAR gene sequence coding the PERV receptors in humans, and were able to express functional receptors for PERV, which implied that dogs



Figure 3 Representative results of reverse transcriptase PCR electrophoresis with the RNA extracted from the plasma. The protease and polymerase gene were found only in circuit 3 before and during treatment. C+, PK15 cells; C-, pure water. The ladder ranged from 100 to $600 \mathrm{bp}$. might be infected by PERV through the same mechanism as humans [25-27].

Reviewing the studies on the microbiological safety of BALs, we found no evidence of crossspecies transmission of PERV in patients treated with porcine BALs or living pig tissue to date [18,28-37]. In previous studies, we did not find any obvious enhanced PERV expression in freshly isolated porcine hepatocytes by chitosan nanofiber scaffold [38,39]. Although a number of studies have investigated the possibility of PERV transmission, no clear conclusion has been drawn. Therefore, viral security is one of the most important issues that must be resolved before our novel extracorporeal BAL system can be used for clinical experiments.

PCR and RT-PCR are the most common methods used to detect PERV transmission [12], and thus were used in the present study. We assessed several pairs of primers reported in previous publications $[15,16,40]$, using them in a number of PCR and RT-PCR assays with nucleic acid extracted from canine cells. The three sets of primers finally used (protease, polymerase, and SsCytB) were chosen because of their high specificity for PERV detection in canine cells (data not shown), and the sensitivity of PCR assays with these three primers has been reported as 0.25 of a PK- 15 cell per $10^{4}$ cells [16], 0.3 of a PK-15 cell per $10^{5}$ cells [29], and 0.25 of a porcine cell per $10^{5}$ cells [16], respectively.

In the current study, PERV RNA, PERV DNA, and reactive RT were detected only in plasma samples taken during circuit 3 of treatment. No activity was found in plasma during circuits 1 or 2, or in PBMCs collected from the dogs. All assays were negative for the porcine-specific SsCytB sequence. These results indicated that there was a possibility of infectious PERV being in the system, but confined to circuit 3. For detection of microchimerism, we carried out PCR with the porcine-specific SsCytB primers [16]. The results were negative for PERV and SsCytB genes, suggesting absence of microchimerism. Furthermore, negative RT activity, consistent with the absence of PERV RNA in the animal plasma, indicated no infection of the animals by PERV, as RT activity is a generic marker for retroviruses [41]. These results are similar to those of Kuddus et al., who reported that the RT activity and PERV RNA were limited to the shell of the bioreactor in their bio-artificial liver support system (BLSS) [30]. In the plasma in circuit 3, we found positive RT activity in all five samples before treatment and in two of the five samples after 3 hours of treatment, but in none of the five samples after 6 hours of treatment. This eventual absence of RT activity may result from the dilution effect of plasma on the reverse transcriptase or from an inhibiting effect of the animal plasma on the RT activity.

An important part of our BAL system is the plasma component separator, which uses semipermeable membranes of 
Table 3 Reverse transcriptasde activity of the plasma at defined time intervals

\begin{tabular}{|c|c|c|c|c|c|}
\hline \multirow[t]{2}{*}{ Time point } & \multicolumn{5}{|l|}{ Beagle } \\
\hline & 1 & 2 & 3 & 4 & 5 \\
\hline Pre-treatment in circuit 3 & Positive* & Positive* & Positive* & Positive* & Positive* \\
\hline After 3 hours of treatment in circuit 3 & Positive* & Negative & Negative & Positive & Negative \\
\hline After 6 hours of treatment in circuit 3 & Negative & Negative & Negative & Negative & Negative \\
\hline Pre-treatment in circuit 2 & Negative & Negative & Negative & Negative & Negative \\
\hline After 3 hours of treatment in circuit 2 & Negative & Negative & Negative & Negative & Negative \\
\hline After 6 hours of treatment in circuit 2 & Negative & Negative & Negative & Negative & Negative \\
\hline Pre-treatment in circuit 1 & Negative & Negative & Negative & Negative & Negative \\
\hline After 3 hours of treatment in circuit 1 & Negative & Negative & Negative & Negative & Negative \\
\hline After 6 hours of treatment in circuit 1 & Negative & Negative & Negative & Negative & Negative \\
\hline Pre-treatment in circuit 1 & Negative & Negative & Negative & Negative & Negative \\
\hline 3 hours after treatment & Negative & Negative & Negative & Negative & Negative \\
\hline 12 hours after treatment & Negative & Negative & Negative & Negative & Negative \\
\hline 24 hours after treatment & Negative & Negative & Negative & Negative & Negative \\
\hline 3 days after treatment & Negative & Negative & Negative & Negative & Negative \\
\hline 5 days after treatment & Negative & Negative & Negative & Negative & Negative \\
\hline 7 days after treatment & Negative & Negative & Negative & Negative & Negative \\
\hline 2 weeks after treatment & Negative & Negative & Negative & Negative & Negative \\
\hline 1 month after treatment & Negative & Negative & Negative & Negative & Negative \\
\hline 3 months after treatment & Negative & Negative & Negative & Negative & Negative \\
\hline 6 months after treatment & Negative & Negative & Negative & Negative & Negative \\
\hline
\end{tabular}

$10 \mathrm{~nm}$, far smaller than the approximately $100 \mathrm{~nm}$ diameter of the retrovirus [42]. Furthermore, the duration of blood perfusion was just 6 hours, thus it is reasonable to infer that the PERV DNA and RNA were removed by the filtration from the collected plasma and PBMCs of the beagles in our study, and thus that no PERV was transmitted across the plasma component separator during the treatment phase. We considered that the lack of PERV transmission in our system is likely to be the result of a combination of no direct contact between the porcine hepatocytes and the dog blood, the small pore size of the semipermeable membranes in the plasma component separator, and the short term of BAL treatment.

We also performed in vitro infection experiments to assess the infectivity of PERV in our system and the infection state of the dogs. Nyberg et al. [43] reported that HEK293 cells could not be infected by the supernatant of in vitro cultured porcine hepatocytes, and that human plasma from patients with fulminant hepatic failure would not affect its infectivity. In other trials, no HEK293 cells were found to be infected in an in vitro infection experiment of another two extracorporeal BAL systems, the Academic Medical Center (AMC)-BAL and the HepatAssist system [18,28]. Similarly, we found no infection of HEK293 cells by PERV in our system.
In conclusion, we found no evidence of PERV infection in our dog model after treatment with our novel BAL support system, suggesting that the system does not pose a risk for PERV transmission. These results indicate that the microbiological safety profile of the system should be sufficient to allow clinical trials. However, BAL treatment of patients would be a more complicated process. Further studies into the microbiological safety of our BAL system in clinical used need to be performed.

\section{Abbreviations \\ BAL: Bio-artificial liver support system; CBC: complete blood count; DMEM: Dulbecco's modified Eagle's medium; ECM: Extracellular matrix; FBS: fetal bovine serum; MSC: Mesenchymal stem cells; PBMC: Peripheral blood mononuclear cell; PBS: Phosphate-buffered saline; PERV: Porcine endogenous retrovirus.}

\section{Competing interests}

The authors declare that they have no competing interests.

\section{Acknowledgement}

This work was funded by the Natural Science Foundation of Jiangsu Province (BK2006008) and the foundation of Medical Center of Jiangsu Province (ZX200605).

\section{Author details}

'Department of Hepatobiliary Surgery, the Affiliated DrumTower Hospital of Nanjing University Medical School, Number 321 Zhongshan Road, Nanjing 210008, China. ${ }^{2}$ Department of Hepatobiliary Surgery, DrumTower Clinical Medical College of Nanjing Medical University, Number 321 Zhongshan 
Road, Nanjing 210008, China. ${ }^{3}$ State Key Laboratory of Bioelectronics, Southeast University, Nanjing 210008, China.

\section{Authors' contributions}

Han B conceived of the study, participated in its design, carried out the virological detection, and coordination and helped to draft the manuscript. Zhang Y, Chu XH, Gu JY carried out the animal experiment, participated in the sequence alignment and drafted the manuscript. Xiao JQ, and Tan JJ were responsible for cell culture. Shi XL participated in the design of the study and performed the statistical analysis. Gu ZZ and Ding YT provided new reagents/analytic tools. All authors read and approved the final manuscript.

Received: 29 November 2011 Accepted: 25 May 2012

Published: 25 May 2012

\section{References}

1. Lee WM, Squires RH Jr, Nyberg SL, Doo E, Hoofnagle JH: Acute liver failure: Summary of a workshop. Hepatology 2008, 47(4):1401-1415.

2. Riordan SM, Williams R: Perspectives on liver failure: past and future. Semin Liver Dis 2008, 28(2):137-141.

3. McKenzie TJ, Lillegard JB, Nyberg SL: Artificial and bioartificial liver support. Semin Liver Dis 2008, 28(2):210-217

4. Carpentier B, Gautier A, Legallais C: Artificial and bioartificial liver devices: present and future. Gut 2009, 58(12):1690-1702.

5. Gerlach JC, Zeilinger K, Patzer li JF: Bioartificial liver systems: why, what whither? Regen Med 2008, 3(4):575-595

6. Chamuleau RA, Deurholt T, Hoekstra R: Which are the right cells to be used in a bioartificial liver? Metab Brain Dis 2005, 20(4):327-335.

7. Tsiaoussis J, Newsome PN, Nelson LJ, Hayes PC, Plevris JN: Which hepatocyte will it be? Hepatocyte choice for bioartificial liver support systems. Liver Transp/ 2001, 7(1):2-10.

8. Kobayashi N, Okitsu T, Tanaka N: Cell choice for bioartificial livers. Keio J Med 2003, 52(3):151-157

9. Armstrong JA, Porterfield JS, De Madrid AT: C-type virus particles in pig kidney cell lines. J Gen Virol 1971, 10(2):195-198

10. Patience $C$, Takeuchi $Y$, Weiss RA: Infection of human cells by an endogenous retrovirus of pigs. Nat Med 1997, 3(3):282-286.

11. Le Tissier PSJ, Takeuchi Y, Patience C, Weiss RA: Two sets of human-tropic pig retrovirus. Nature 1997, 389(6652):681-682

12. Wilson CA: Porcine endogenous retroviruses and xenotransplantation. Cell Mol Life Sci 2008, 65(21):3399-3412.

13. Chu XH, Shi XL, Feng ZQ, Gu JY, Xu HY, Zhang Y, Gu ZZ, Ding YT: In vitro evaluation of a multi-layer radial-flow bioreactor based on galactosylated chitosan nanofiber scaffolds. Biomaterials 2009, 30(27):4533-4538.

14. Gu J, Shi X, Zhang Y, Ding Y: Heterotypic interactions in the preservation of morphology and functionality of porcine hepatocytes by bone marrow mesenchymal stem cells in vitro. J Cell Physiol 2009, 219(1):100-108.

15. Moscoso I, Hermida-Prieto M, Manez R, Lopez-Pelaez E, Centeno A, Diaz TM, Domenech N: Lack of cross-species transmission of porcine endogenous retrovirus in pig-to-baboon xenotransplantation with sustained depletion of anti-alphagal antibodies. Transplantation 2005 79(7):777-782.

16. Blusch $\mathrm{JH}$, Roos $\mathrm{C}$, Nitschko $\mathrm{H}$ : A polymerase chain reaction-based protocol for the detection of transmission of pig endogenous retroviruses in pig to human xenotransplantation. Transplantation 2000, 69(10):2167-2172

17. Galbraith DN, Kelly HT, Dyke A, Reid G, Haworth C, Beekman J, Shepherd A, Smith KT: Design and validation of immunological tests for the detection of Porcine endogenous retrovirus in biological materials. $J$ Virol Methods 2000, 90(2):115-124.

18. Di Nicuolo G, van de Kerkhove MP, Hoekstra R, Beld MG, Amoroso P, Battisti S, Starace M, di Florio E, Scuderi V, Scala S, et al: No evidence of in vitro and in vivo porcine endogenous retrovirus infection after plasmapheresis through the AMC-bioartificial liver. Xenotransplantation 2005, 12(4):286-292.

19. Argaw T, Colon-Moran W, Wilson CA: Limited infection without evidence of replication by porcine endogenous retrovirus in guinea pigs. J Gen Virol 2004, 85(Pt 1):15-19.
20. van der Laan LJ, Lockey C, Griffeth BC, Frasier FS, Wilson CA, Onions DE, Hering BJ, Long Z, Otto E, Torbett BE, et al: Infection by porcine endogenous retrovirus after islet xenotransplantation in SCID mice. Nature 2000, 407(6800):90-94.

21. Deng YM, Tuch BE, Rawlinson WD: Transmission of porcine endogenous retroviruses in severe combined immunodeficient mice xenotransplanted with fetal porcine pancreatic cells. Transplantation 2000, 70(7):1010-1016.

22. Clemenceau B, Jegou D, Martignat L, Sai P: Microchimerism and transmission of porcine endogenous retrovirus from a pig cell line or specific pathogen-free pig islets to mouse tissues and human cells during xenografts in nude mice. Diabetologia 2002, 45(6):914-923.

23. Yang YG, Wood JC, Lan P, Wilkinson RA, Sykes M, Fishman JA, Patience C: Mouse retrovirus mediates porcine endogenous retrovirus transmission into human cells in long-term human-porcine chimeric mice. J Clin Invest 2004, 114(5):695-700.

24. Martina Y, Kurian S, Cherqui S, Evanoff G, Wilson C, Salomon DR: Pseudotyping of porcine endogenous retrovirus by xenotropic murine leukemia virus in a pig islet xenotransplantation model. Am J Transplant 2005, 5(8):1837-1847.

25. Ericsson TA, Takeuchi Y, Templin C, Quinn G, Farhadian SF, Wood JC, Oldmixon BA, Suling KM, Ishii JK, Kitagawa Y, et al: Identification of receptors for pig endogenous retrovirus. Proc Natl Acad Sci U S A 2003, 100(11):6759-6764.

26. Takeuchi Y, Patience C, Magre S, Weiss RA, Banerjee PT, Le Tissier P, Stoye JP: Host range and interference studies of three classes of pig endogenous retrovirus. J Virol 1998, 72(12):9986-9991.

27. Mattiuzzo G, Matouskova M, Takeuchi Y: Differential resistance to cell entry by porcine endogenous retrovirus subgroup $A$ in rodent species. Retrovirology 2007, 4:93

28. Pitkin Z, Mullon C: Evidence of absence of porcine endogenous retrovirus (PERV) infection in patients treated with a bioartificial liver support system. Artif Organs 1999, 23(9):829-833.

29. Paradis K, Langford G, Long Z, Heneine W, Sandstrom P, Switzer WM Chapman LE, Lockey C, Onions D, Otto E: Search for cross-species transmission of porcine endogenous retrovirus in patients treated with living pig tissue. The XEN 111 Study Group. Science 1999, 285(5431):1236-1241.

30. Kuddus R, Patzer JF 2nd, Lopez R, Mazariegos GV, Meighen B, Kramer DJ, Rao AS: Clinical and laboratory evaluation of the safety of a bioartificial liver assist device for potential transmission of porcine endogenous retrovirus. Transplantation 2002, 73(3):420-429.

31. van de Kerkhove MP, Di Florio E, Scuderi V, Mancini A, Belli A, Bracco A, Scala D, Scala S, Zeuli L, Di Nicuolo G, et al: Bridging a patient with acute liver failure to liver transplantation by the AMC-bioartificial liver. Cell Transplant 2003, 12(6):563-568

32. Di Nicuolo G, D'Alessandro A, Andria B, Scuderi V, Scognamiglio M, Tammaro A, Mancini A, Cozzolino S, Di Florio E, Bracco A, et al: Longterm absence of porcine endogenous retrovirus infection in chronically immunosuppressed patients after treatment with the porcine cell-based Academic Medical Center bioartificial liver. Xenotransplantation 2010, 17(6):431-439.

33. Irgang M, Sauer IM, Karlas A, Zeilinger K, Gerlach JC, Kurth R, Neuhaus P, Denner J: Porcine endogenous retroviruses: no infection in patients treated with a bioreactor based on porcine liver cells. J Clin Virol 2003, 28(2):141-154.

34. Sauer IM, Kardassis D, Zeillinger K, Pascher A, Gruenwald A, Pless G, Irgang M, Kraemer M, Puhl G, Frank J, et al: Clinical extracorporeal hybrid liver support-phase I study with primary porcine liver cells. Xenotransplantation 2003, 10(5):460-469.

35. Abu-Absi SF, Seth G, Narayanan RA, Groehler K, Lai P, Anderson ML, Sielaff T, Hu WS: Characterization of a hollow fiber bioartificial liver device. Artif Organs 2005, 29(5):419-422.

36. Wang HH, Wang YJ, Liu HL, Liu J, Huang YP, Guo HT, Wang YM: Detection of PERV by polymerase chain reaction and its safety in bioartificial liver support system. World J Gastroenterol 2006, 12(8):1287-1291.

37. Liu Q, Liu Z, Dalakas E: Prevalence of porcine endogenous retrovirus in Chinese pig breeds and in patients treated with a porcine liver cell-based bioreactor. World J Gastroenterol 2005, 11(30):4727-4730

38. Han B, Shi X, Gu ZZ, Xiao J, Chu X, Gu J, Zhang Y, Tan J, Ding Y: No enhanced expression and infectivity of porcine endogenous retrovirus in 
primary porcine hepatocytes with chitosan nanofiber scaffold. J Biomed Nanotechnol 2011, 7(3):377-383.

39. Han B, Shi XL, Xiao JQ, Zhang Y, Chu XH, Gu JY, Tan JJ, Gu ZZ, Ding YT: Influence of chitosan nanofiber scaffold on porcine endogenous retroviral expression and infectivity in pig hepatocytes. World J Gastroenterol 2011, 17(22):2774-2780.

40. Switzer WM, Shanmugam V, Chapman L, Heneine W: Polymerase chain reaction assays for the diagnosis of infection with the porcine endogenous retrovirus and the detection of pig cells in human and nonhuman recipients of pig xenografts. Transplantation 1999, 68(2):183-188.

41. Heneine W, Tibell A, Switzer WM, Sandstrom P, Rosales GV, Mathews A Korsgren O, Chapman LE, Folks TM, Groth CG: No evidence of infection with porcine endogenous retrovirus in recipients of porcine islet-cell xenografts. Lancet 1998, 352(9129):695-699.

42. Nyberg SL, Hibbs JR, Hardin JA, Germer JJ, Persing DH: Transfer of porcine endogenous retrovirus across hollow fiber membranes: significance to a bioartificial liver. Transplantation 1999, 67(9):1251-1255.

43. Nyberg SL, Hibbs JR, Hardin JA, Germer JJ, Platt JL, Paya CV, Wiesner RH: Influence of human fulminant hepatic failure sera on endogenous retroviral expression in pig hepatocytes. Liver Transp/ 2000, 6(1):76-84.

doi:10.1186/2047-783X-17-13

Cite this article as: Han et al: Microbiological safety of a novel bioartificial liver support system based on porcine hepatocytes: a experimental study. European Journal of Medical Research 2012 17:13.

\section{Submit your next manuscript to BioMed Central and take full advantage of:}

- Convenient online submission

- Thorough peer review

- No space constraints or color figure charges

- Immediate publication on acceptance

- Inclusion in PubMed, CAS, Scopus and Google Scholar

- Research which is freely available for redistribution 